\title{
The effect of omega-3 on muscle and non-muscle cells on a 2D fibronectin and in 3D fibrin constructs
}

\begin{abstract}
Human Foreskin Fibroblasts (HFF-1) and L6 muscle cells were treated in several conditions to examine the proliferation and adhesion of cells using different extracellular matrix proteins with different concentrations. These proteins consist of Collagen \& Fibronectin with concentrations of $5 \mathrm{ug} / \mathrm{ml}$ and $10 \mathrm{ug} / \mathrm{ml}$ respectfully. The experiment was conducted and focused on how HFF-1 and L6 cells proliferate in two different conditions over a 7-day period and the results were recorded on Days $1,3 \& 7(n=9)$. Different concentrations of Fibronectin and Collagen altered the proliferation of HFF-1 cells over a 7-day period. Once it was identified that the best proliferation of HFF-1 and L6 was the Fibronectin $10 \mathrm{ug} / \mathrm{mL}$ coating, we used the same protein matrix to study the effects of different concentrations of Generic Omega-3 in cell adhesion and proliferation. Throughout the study, it is observed that proliferation is not proportional to the Omega- 3 concentration, meaning in this study 1 $\mathrm{mg} / \mathrm{ml}$ had the lowest proliferation. In conclusion from the first study, higher concentrations of Generic Omega-3 decreases the proliferation of HFF-1 and L6 cells. This is a known characteristic as Omega-3 inhibits cell proliferation by prolonging the G1 phase but did not arrest the G0-to-G1 or G1-to-S transitions. The prolonged G1 phase in fad3b ESCs was probably induced by downregulation of Cdk4 expression via p21 upregulation. In comparison to the Generic product of Omega-3 we decided to incorporate the Synthetic substance of Omega-3 into the study. The overall goal of this experiment was to observe the proliferation and adhesion of HFF-1 and L6 cells in artificially created media containing pure Synthetic Omega-3 fatty acids. This experiment was repeated three times $(n=9)$ to gain valuable conclusive data which could be used to design future experiments. An additional experiment was specifically designed to see how HFF-1 and L6 cells migrate through a thick 3-D layer of fibrin. Fibrin is a substance formed through catalytic conversion of coagulation constituents: fibrinogen and thrombin. This experiment was conducted, and the results were taken for Day 1 and Day 7. Our results remained consistent in comparison to prior studies. With the use of higher concentrations of Synthetic Omega-3 there was a decrease in proliferation for both HFF-1 and L6 cells.
\end{abstract}

Keywords: HFF-1 cells, L6 muscle cells, fibronectin, collagen, omega-3, 3D fibrin
Volume 7 Issue 3 - 2020

\author{
Sozzi Simon,' Souza Danilo,' Sidhu \\ Karandeep,' 'Garcia Victor,' Tawil Bill,', \\ 'Department of Biotechnology and Bioinformatics, California \\ State University, USA \\ ${ }^{2}$ Department of Biomedical Engineering, University of California \\ Los Angeles, USA
}

Correspondence: Bill Tawil, Department of Bioengineering, UCLA School of Engineering, 420 Westwood Plaza, Room 5I2I, Engineering V. P.O. Box: 951600, Los Angeles, CA 90095-1600, USA, Fax (310) 794-5956, Email bill.tail@csuci.edu

Received: May 17, 2020 | Published: June 12, 2020
Abbreviations: HFF, human foreskin fibroblasts; ECM, extracellular matrix; PBS, phosphate buffer saline

\section{Introduction}

Omega-3 fatty acids are present in certain foods such as flaxseed and fish, as well as dietary supplements such as fish oil. Omega-3 fatty acids have been popularized because of their important roles in human health and development. ${ }^{1-9}$ Omega-3 can also play an important role in human diseases. Eicosatetraenoic acid (EPA) and docosahexaenoic acid (DHA) are Omega-3 (n-3) fatty acids found in oily fish and fish oil supplements. ${ }^{10-12}$ In this study we examine the proliferation and adhesion of Human Foreskin Fibroblasts (HFF-1) and L6 muscle cells in the presence of Generic and Synthetic Omega-3. HFF-1 cells as well as L6 cells have proven to be efficient and easy to handle when doing research studies. As a muscle and non-muscle cells they were chosen to understand the impact of Omega-3 in cell adhesion and proliferation. Fibronectin was confirmed to promote cell adhesion at initial phase, in this study day 1 . Fibronectin is a glycoprotein of the extracellular matrix that binds to membrane-spanning matrix proteins called integrins. Although Fibronectin has been studies for more than two decades, this remarkably complex molecule is still the subject of exciting discoveries. ${ }^{8}$ Studies conducted in the past have shown that fibronectin plays a major role in cell adhesion, growth, migration and differentiation. The concentration of Fibronectin can influence the different percentages of growth observed in HFF-1 cells as well as L6 cells. Fibroblasts adhesion to fibrin requires fibronectin, this is important especially in wound healing which Fibronectin has an influence on. A 3D matrix consisting of Fibrinogen and Thrombin was also conducted to show the adhesion and proliferation of HFF1/L6 cells in the presence of Omega-3. Changing the kinetics of the constituents determines the structural properties of the fibrin architecture. ${ }^{7}$ Note that 3D models are more like a live biological model as well as allow better understanding of the geometric models of the proteins produced by the cells in study. The relationship between fibrin microstructure, rate of polymerization and structural stiffness have been studied extensively. ${ }^{7}$

\section{Materials \& methods}

Cell culture of HFF-1 cells: Human Foreskin Fibroblast (HFFs) were cultured in Dulbecco's Modified Eagle Medium (DMEM) containing $10 \%$ fetal bovine serum (FBS) in a flask kept at 37 degrees Celsius and $5 \% \mathrm{CO}_{2}$ by use of a Thermo Scientific incubator for our starting materials. After confirmation of proper confluency of HFF- 
1 cells maintained in a $75 \mathrm{~mL}$ flask via microscope, the old media was removed. two washes were performed with the addition of $5 \mathrm{~mL}$ of sterile Phosphate Buffer Saline (PBS) $1 X \&$ removed. $5 \mathrm{~mL}$ of trypsin was added $\&$ left to incubate for 5 minutes. In order to ensure detachment of cells from the flask, examination under a microscope was done. To stop trypsin activity, $5 \mathrm{~mL}$ of HFF-1 media was added to the flask. The total suspension of $10 \mathrm{~mL}$ was added to a conical tube \& centrifuged at $200 \mathrm{rpm}$ for 5 minutes. The supernatant was removed $\&$ the remaining pellet was resuspended in $1 \mathrm{~mL}$ of HFF-1 media. Two $20 \mathrm{uL}$ samples of stock cell mixture was added to a disposable cellometer counting chamber slide and analyzed for cell count and concentration with the Nexcelom Cellometer Auto T4 \& the average cell concentration was obtained. ${ }^{13-20}$

Cell culture of L6 muscle cells: L6 Muscle cells were cultured in Dulbecco's Modified Eagle Medium (DMEM) containing 10\% fetal bovine serum (FBS) in a flask kept at 37 degrees Celsius and 5\% $\mathrm{CO}_{2}$ by use of a Thermo Scientific incubator for our starting materials. After confirmation of proper confluency of L6 cells maintained in a $75 \mathrm{~mL}$ flask via microscope, the old media was removed. Two washes were performed with the addition of $5 \mathrm{~mL}$ of sterile Phosphate Buffer Saline (PBS) $1 \mathrm{X} \&$ removed. $5 \mathrm{~mL}$ of trypsin was added \& left to incubate for 5 minutes. To ensure detachment of cells from the flask, examination under a microscope was done. To stop trypsin activity, $5 \mathrm{~mL}$ of HFF-1 media was added to the flask. The total suspension of $10 \mathrm{~mL}$ was added to a conical tube \& centrifuged at $200 \mathrm{rpm}$ for 5 minutes. The supernatant was removed $\&$ the remaining pellet was resuspended in $1 \mathrm{~mL}$ of L6 media. Two $20 \mathrm{uL}$ samples of stock cell mixture was added to a disposable cellometer counting chamber slide and analyzed for cell count and concentration with the Nexcelom Cellometer Auto T4 \& the average cell concentration was obtained.

Proliferation of HFF-1 cells: For proliferation assay, cells were seeded in 24 well plates, coated with either no substrate, collagen at concentrations of $5 \mathrm{ug} / \mathrm{ml}$, and $10 \mathrm{ug} / \mathrm{ml}$ and fibronectin at concentration of $5 \mathrm{ug} / \mathrm{ml}$, 10ug.ml, of each substrate type in triplicate. The wells were loaded with an initial density of 10,000 cells per well and stored at 37 degrees C. After 0,3 , and 7 days of incubation cells were washed with PBS twice and incubated for 15 minutes in a dark area with $200 \mathrm{ul}$ of Calcein AM stain. Fluorescent samples were then quantified using a FilterMax F5 Multimode Microplate reader. Image acquisition was performed using an inverted microscope equipped with QImaging camera and QCapture Pro imaging software at 10x objective.

Proliferation of L6 muscle cells: For proliferation assay, cells were seeded in 24 well plates, coated with either no substrate, collagen at concentrations of $5 \mathrm{ug} / \mathrm{ml}$, and $10 \mathrm{ug} / \mathrm{ml}$ and fibronectin at concentration of $5 \mathrm{ug} / \mathrm{ml}, 10 \mathrm{ug} . \mathrm{ml}$, of each substrate type in triplicate. The wells were loaded with an initial density of 10,000 cells per well and stored at 37 degrees C. After 0,3, and 7 days of incubation cells were washed with PBS twice and incubated for 15 minutes in a dark area with $200 \mathrm{ul}$ of Calcein AM stain. Fluorescent samples were then quantified using a FilterMax F5 Multimode Microplate reader. Image acquisition was performed using an inverted microscope equipped with QImaging camera and QCapture Pro imaging software at 10x objective.

Omega-3 preparation: Cells were seeded in 24 well plates, coated with $10 \mathrm{ug} / \mathrm{ml}$ of Fibronectin at 4 different concentrations of Omega3; $0 \mathrm{mg}, 1 \mathrm{mg}$, $5 \mathrm{mg}$ and $10 \mathrm{mg}$. Ethanol was used to dissolve the Omega 3. Media was then added to reach a total volume of $2 \mathrm{~mL}$. The wells were loaded with an initial density of cells per well and stored at 37 degrees C. After 0,3 , and 7 days of incubation cells were washed with PBS twice and incubated for 15 minutes in a dark area with $200 \mathrm{ul}$ of Calcein AM stain. Fluorescent samples were then quantified using a FilterMax F5 Multimode Microplate reader. Image acquisition was performed using an inverted microscope equipped with QImaging camera and QCapture Pro imaging software at 10x. ${ }^{21-29}$

2D cell adhesion/ proliferation with omega-3: A 24-well plate was coated with fibronectin at $10 \mathrm{ug} / \mathrm{mL}$. A cell dilution calculation was done targeting 10000 cells per well. An Omega 3, from a GMC Omega 3 pill with $1000 \mathrm{mg}$ per capsule was BTV to $4 \mathrm{ml}$ of solution in alcohol and later $0.100 \mathrm{ml}$ of this solution was added to a solution of $10 \mathrm{ml}$ of media. The new solution was filtered and used to extract two sets $0,0.1 \mathrm{mg} / \mathrm{ml}, 0.5 \mathrm{mg} / \mathrm{ml}, 0.10 \mathrm{mg} / \mathrm{ml}$ in two phases using synthetic and commercial Omega 3 respectively. In one set of each condition, it was added 10000 cells and later distributed $1 \mathrm{ml}$ of each condition $3 \mathrm{x}$ in 3 different plates (day 0,3 and 7 plates). After $1 \mathrm{hr}$ of incubation, the plate for day 0 was washed with $0.5 \mathrm{~mL}$ of PBS twice and incubated for 15 minutes with $200 \mathrm{ul}$ of calcein AM stain Fluorescent. The samples were then quantified using a FilterMax F5 Multimode Microplate reader. Image acquisition was performed using an inverted microscope equipped with QImaging camera and QCapture Pro imaging software at 10X objective.

3D cell adhesion/ proliferation with omega-3: A 24-well plate was prepared using $250 \mathrm{ml}$ of Thrombin $20 \mathrm{mg} / \mathrm{ml}$ plus $10 \mathrm{k}$ cells as well as $250 \mathrm{ml}$ of Fibronectin $50 \mathrm{u} / \mathrm{ml}$. An Omega 3, from a GMC Omega 3 pill with $1000 \mathrm{mg}$ per capsule was BTV to $4 \mathrm{ml}$ of solution in alcohol and later $0.100 \mathrm{ml}$ of this solution was added to a solution of $10 \mathrm{ml}$ of media. The new solution was filtered and used to extract two sets 0 , $0.1 \mathrm{mg} / \mathrm{ml}, 0.5 \mathrm{mg} / \mathrm{ml}, 0.10 \mathrm{mg} / \mathrm{ml}$ in two phases using synthetic and commercial Omega 3 respectively. This was done in two plates, day 1 and day 7 . After $1 \mathrm{hr}$ of incubation, the plate for day incubated for 15 minutes with 400ul of calcein AM stain Fluorescent. The samples were then quantified using a FilterMaxF5 Multimode Microplate reader. Image acquisition was performed using an inverted microscope equipped with QImaging camera and QCapture Pro imaging software at $10 \mathrm{X}$ objective.

\section{Results}

\section{HFF-I cell proliferation increases more on fibronectin than collagen}

Human Foreskin Fibroblasts (HFF-1) were treated in two conditions to examine the proliferation and adhesion of cells. The two conditions consisted of Collagen and Fibronectin at two different concentrations to measure the initial adhesion and proliferation of HFF-1 cells. A 7-day experiment was conducted and ran twice to measure the interaction between the HFF cells, and the proteins expressed. As seen, $5 \mathrm{ug} / \mathrm{mL}$ of Collagen had the best cell adhesion compared to $5 \mathrm{ug} / \mathrm{mL}$ and $10 \mathrm{ug} / \mathrm{mL}$ of Fibronectin. Fibronectin at $10 \mathrm{ug} / \mathrm{mL}$ had the lowest cell adhesion and to contrary had the highest cell proliferation. The proliferation was seen best on 10ug/ $\mathrm{mL}$ of Fibronectin. With the results seen we decided to experiment with $10 \mathrm{ug} / \mathrm{mL}$ Fibronectin for further studies. HFF-1 cells under the exposure of calcein were captured using a microscope capable of detecting fluorescence as shown in Figure 1. The cell morphology illustrates that the HFF-1 cells reach full confluency by Day 7. The cells are however more confluent on $10 \mathrm{ug} / \mathrm{mL}$ of Fibronectin. 


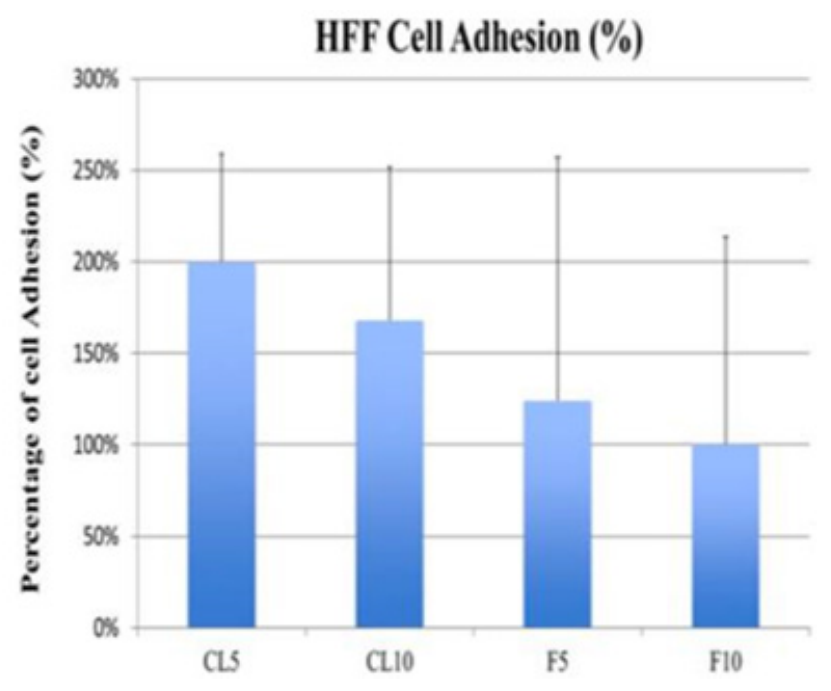

Figure I (a) HFF Cell Adhesion Percentage: $5 \mathrm{ug} / \mathrm{mL}$ of Collagen had the best cell adhesion compared to $5 \mathrm{ug} / \mathrm{mL}$ and $10 \mathrm{ug} / \mathrm{mL}$ of Fibronectin. Experiment was ran 3 times.

\section{HFF Cell Proliferation (\%)}

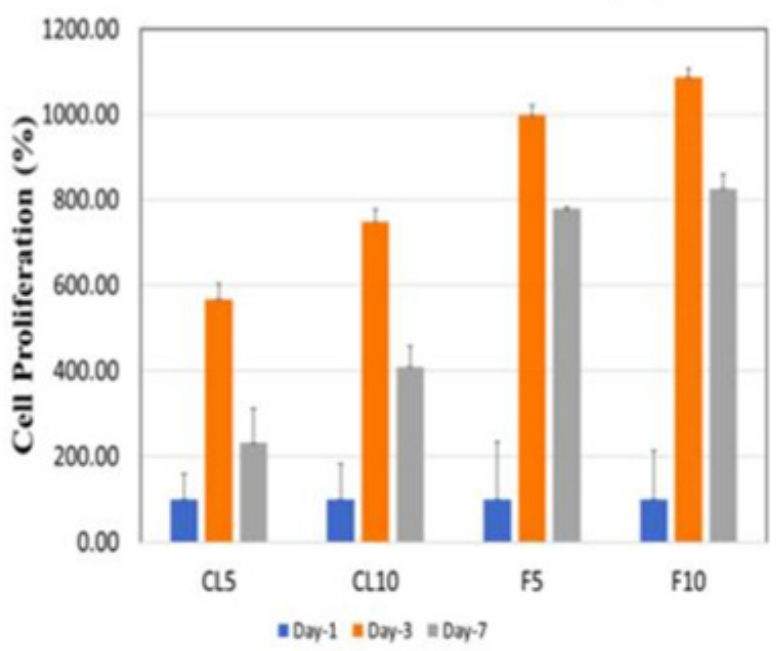

Figure I (b) HFF Cell Percent Proliferation: HFF cell proliferation, on Day I, 3 \& 7, using Collagen and Fibronectin on concentrations of $5 \mathrm{ug} / \mathrm{mL} \& 10 \mathrm{ug} /$ $\mathrm{mL}$ was observed that the best results were for Fibronectin $10 \mathrm{ug} / \mathrm{mL}$, and the peak values were seen on day 3 for all concentrations and protein matrix.

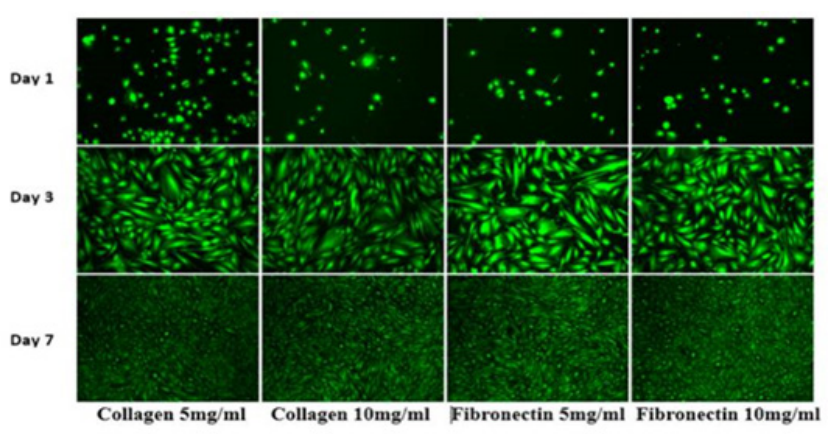

Figure I (c) Calcein Stained HFF Cells Fluorescent Images:HFF cells under exposure of calcine using a microscope capable of detecting fluorescence to have a visual reference of cell proliferation.

\section{Higher concentrations of generic omega-3 decreases the initial adhesion and proliferation of HFF-I and L6 cells on 2D fibronectin}

\section{HFF-I cells}

HFF-1 cells were treated on a $10 \mathrm{ug} / \mathrm{mL}$ Fibronectin matrix in the presence of Generic Omega-3 to examine the initial adhesion and proliferation. Generic Omega-3 concentrations were determined and placed in their respective wells. The concentrations of Generic Omega-3; 0, 0.1, 0.5 and $1 \mathrm{mg} / \mathrm{mL}$ respectively. The cells were plated on 3 different days of incubation to analyze the initial adhesion and proliferation. After one hour of incubation our results showed that higher concentrations of Omega-3 decreased the initial adhesion of HFF-1 cells. $0.1 \mathrm{mg} / \mathrm{mL}$ had the highest initial adhesion seen in HFF-1 cells compared to $0.5 \mathrm{mg} / \mathrm{mL}$ and $1 \mathrm{mg} / \mathrm{mL}$ as seen in Figure 2 (A-C). HFF-1 cell proliferation was also recorded and the higher concentrations of Generic Omega-3 increased the proliferation of HFF cells. The highest percentage of proliferation can be seen with the concentration of $1 \mathrm{mg} / \mathrm{mL}$ on Day 4. The cell morphology remained consistent with higher confluency in the presence of $1 \mathrm{mg} / \mathrm{mL}$ of Generic Omega-3. The proliferation of HFF-1 cells seemed to decrease from Day 4 to Day 7 in all concentrations of Generic Omega-3. HFF-1 cells were under exposure of calcein using a microscope capable of detecting fluorescence to have a visual reference of cell proliferation. Further comparisons will be made with L6 cells to determine if the various concentrations of Omega- 3 impact the cell morphology of HFF-1 cells.
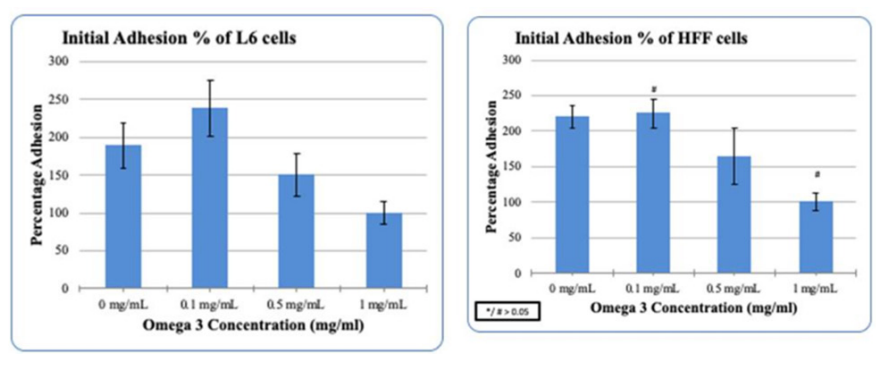

Figure 2 (a \&b) HFF/L6 cell adhesion in the presence of Commercial Omega3:Higher concentrations of Omega-3 decreased the adhesion of HFF/L6 cells.

\section{L6 cells}

L6 muscle cells were treated on a $10 \mathrm{ug} / \mathrm{mL}$ Fibronectin matrix in the presence of Generic Omega-3 to examine the initial adhesion and proliferation. Generic Omega-3 concentrations were determined and placed in their respective wells. The concentrations of Generic Omega-3; $0,0.1,0.5$ and $1 \mathrm{mg} / \mathrm{mL}$ respectively. The cells were plated on 3 different days of incubation to analyze the initial adhesion and proliferation. This study was done in comparison to HFF-1 cells in various concentrations of Generic Omega-3. Higher concentrations of Generic Omega-3 decreased the adhesion of L6 muscle cells. The highest L6 initial adhesion was seen in $0.1 \mathrm{mg} / \mathrm{mL}$ compared to the other concentrations of Generic Omega-3. Previously our results showed that higher concentrations of Generic Omega- 3 increase the proliferation of HFF-1 cells, but in the case of L6 cells, the opposite occurred. Higher concentrations of Generic Omega-3 decreased the proliferation of L6 muscle cells. As seen in Figure 2D, the viable cell count decreases at the concentration of $1 \mathrm{mg} / \mathrm{mL}$ compared to $0.1 \mathrm{mg} /$ $\mathrm{mL}$ of Generic Omega-3 which had the highest proliferation. Figure $2 \mathrm{E}$ shows the L6 cell morphology in the presence of Generic Omega-3. 
Higher concentrations of Generic Omega- 3 resulted in a decrease of L6 cell proliferation on Day 7. The L6 cells seem to reach the highest confluency at $0.1 \mathrm{mg} / \mathrm{mL}$ which remains consistent with the data measure for proliferation. The cells were also exposed to calcein and using a microscope capable of detecting fluorescence the proliferation of the L6 cells were visually identified.
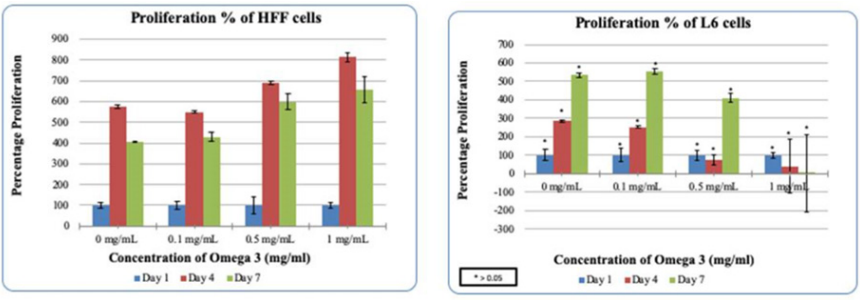

Figure 2 (c \& d) HFF/L6 cell proliferation in the presence of Omega-3: Higher concentrations of Omega-3 increase the proliferation of HFF cells and decreases $\mathrm{L} 6$ cells.
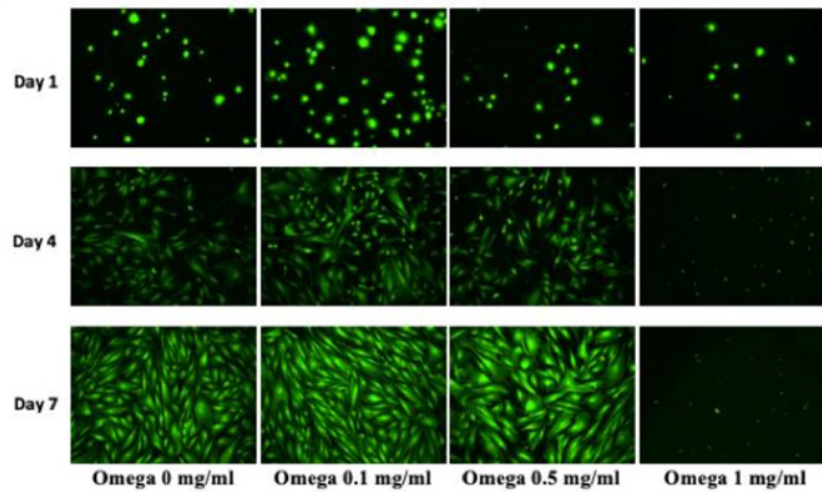

Figure 2 (e) HFF Cells Under Calcein Exposure:HFF cells under exposure of calcein using a microscope capable of detecting fluorescence to have a visual reference of cell proliferation.

\section{Higher concentrations of synthetic omega-3 decreases the adhesion and proliferation of HFF-I and L6 cells on 2D fibronectin}

\section{HFF-I Cells}

HFF-1 cells were treated with Synthetic Omega-3 on a $10 \mathrm{ug} / \mathrm{mL}$ Fibronectin matrix in the presence to examine the initial adhesion and proliferation. Synthetic Omega-3 concentrations were determined and placed in their respective wells. The concentrations of Generic Omega-3; 0, 0.1, 0.5 and $1 \mathrm{mg} / \mathrm{mL}$ respectively. The cells were plated on 3 different days of incubation to analyze the initial adhesion and proliferation. This study was done to compare the impact of HFF1 cell in the presence of Generic and Synthetic Omega-3 on 10ug/ $\mathrm{mL}$ Fibronectin. After one hour of incubation our results showed that higher concentrations of Synthetic Omega-3 decreased the initial adhesion of HFF-1 cells. $0 \mathrm{mg} / \mathrm{mL}$ of Synthetic Omega- 3 had the highest initial adhesion seen in HFF-1 cells compared to $1 \mathrm{mg} /$ $\mathrm{mL}$ as seen in Figure 3. HFF-1 cell proliferation was also recorded and the higher concentrations of Synthetic Omega-3 decreased the proliferation of HFF-1 cells. This was an interesting finding because the higher concentrations of Generic Omega-3 seemed to increase the proliferation of HFF-1 cells in our prior studies. The highest percentage of proliferation can be seen with the concentration of $0 \mathrm{mg}$ / $\mathrm{mL}$ on Day 7. The cell morphology remained consistent with higher confluency in the presence of $0 \mathrm{mg} / \mathrm{mL}$ of Generic Omega- 3 compared to $1 \mathrm{mg} / \mathrm{mL}$ of Synthetic Omega-3 on Day 7. The proliferation of HFF-
1 cells seemed to decrease from Day 4 to Day 7 in all concentrations of Generic Omega-3. Cells remained rounded throughout the concentrations of Synthetic Omega-3 which led us to believe there was not much of an impact in cell morphology. HFF-1 cells were under exposure of calcein using a microscope capable of detecting fluorescence to have a visual reference of cell proliferation.
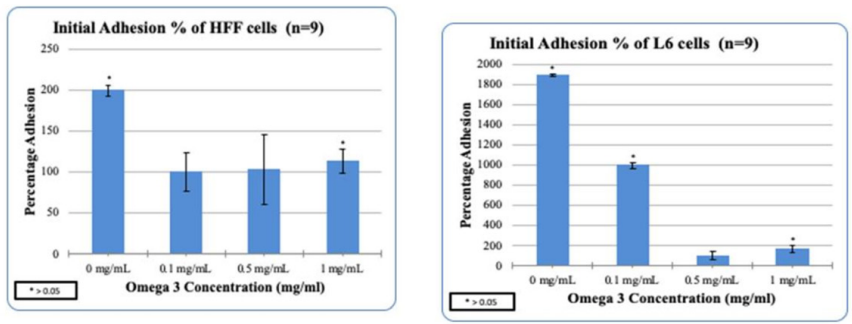

Figures 3 (a \& b) HFF/L6 cell adhesion in the presence of Synthetic Omega-3: Higher concentrations of Omega-3 decreased the adhesion of HFF/L6 cells.
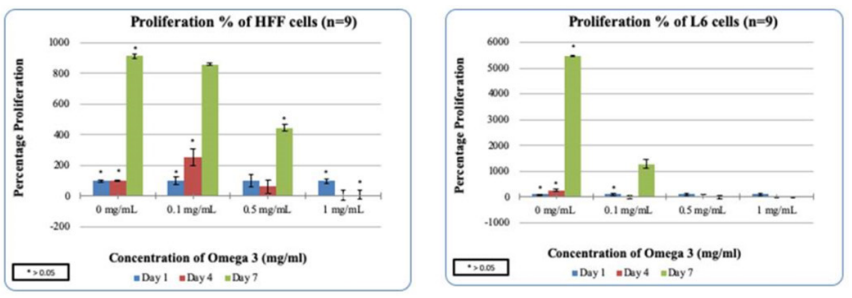

Figures 3 (c \& d) HFF/L6 cell proliferation in the presence of Omega-3: Higher concentrations of Omega-3 decrease the proliferation of HFF/L6 cells.
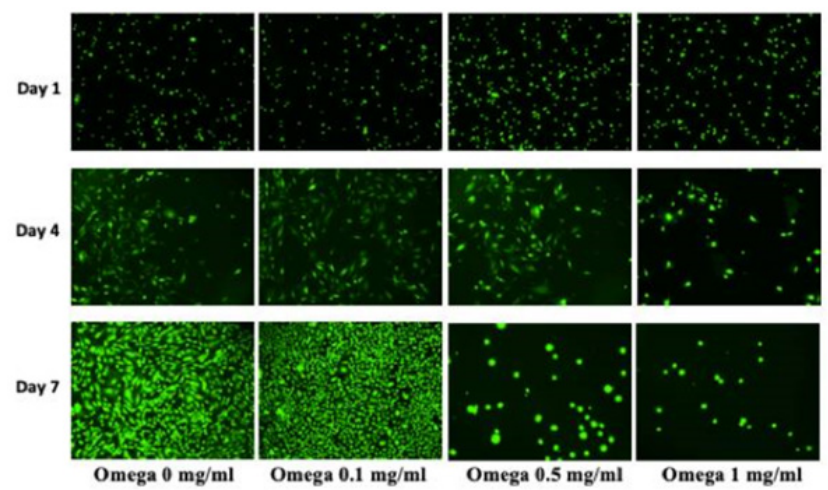

Figure 3 (e) Fluorescence Images of Calcein Stained L6 Cells:L6 cells under exposure of calcein using a microscope capable of detecting fluorescence to have a visual reference of cell proliferation.

\section{L6 cells}

L6 muscle cells were treated on a $10 \mathrm{ug} / \mathrm{mL}$ Fibronectin matrix in the presence of Generic Omega-3 to examine the initial adhesion and proliferation. Synthetic Omega-3 concentrations were determined and placed in their respective wells. The concentrations of Synthetic Omega-3; 0, 0.1, 0.5 and $1 \mathrm{mg} / \mathrm{mL}$ respectively. The cells were plated on 3 different days of incubation to analyze the initial adhesion and proliferation. This study was done in comparison to HFF-1 cells in various concentrations of Synthetic Omega-3. Higher concentrations of Synthetic Omega- 3 decreased the adhesion of L6 muscle cells. The highest L6 initial adhesion was seen in $0 \mathrm{mg} / \mathrm{mL}$ compared to the other concentrations of Synthetic Omega-3. Previously our results showed that higher concentrations of Generic Omega-3 decreased the proliferation of HFF-1 cells and this case remained consistent in L6 cells. Higher concentrations of Synthetic Omega-3 decreased the proliferation of L6 muscle cells. As seen in Figure 3, the viable 
cell count decreases at the concentration of $1 \mathrm{mg} / \mathrm{mL}$ compared to $0 \mathrm{mg} / \mathrm{mL}$ on Day 7 of Synthetic Omega-3 which had the highest proliferation. The L6 cell morphology in the presence of Synthetic Omega-3 was captured and analyzed. Higher concentrations of Synthetic Omega-3 resulted in a decrease of L6 cell proliferation on Day 7. The L6 cells seem to reach the highest confluency at $0 \mathrm{mg} / \mathrm{mL}$ which remains consistent with the data measured for proliferation. The cells were also exposed to calcein and using a microscope capable of detecting fluorescence the proliferation of the L6 cells were visually identified.

\section{HFF-I cells proliferate more in FI O/T I 00 3D construct}

HFF-1 cells were measured for proliferation and adhesion in a Fibrinogen and Thrombin 3D construct. This construct consisting of Fibrinogen and Thrombin forms a 3D environment for the cells known as Fibrin. Different concentrations were examined to determine which environment would be optimal for the adhesion and proliferation of HFF-1 cells. The data shows that the best proliferation is seen on the lower concentrations of Fibrinogen and higher concentrations of Thrombin. This is in accordance with what is seen in the literature, as when there are higher concentrations of Fibrinogen in the polymer, the porosity is lower, therefore promotes lower cell proliferation than the values seen with lower concentrations. There is no statistical difference seen in Figure 4. The HFF-1 cells seemed to adhere and proliferate best in the concentration of F10/T100 as seen in Figure 4A. L6 cells were also analyzed to gain a better understanding. The results seen concluded that L6 cells adhered best in F10/T100 as seen in Figure 4B and had an increase of proliferation in F10/T50.

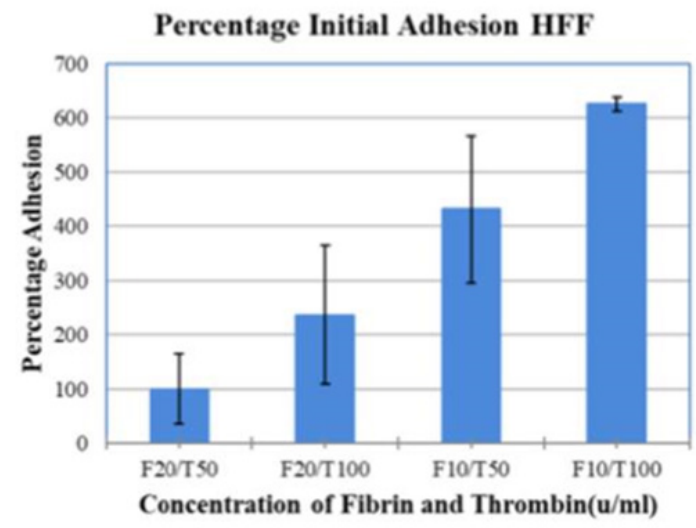

Figure 4 (a) HFF cell adhesion in several combinations of Fibrinogen and Thrombin:The best Adhesion was seen in FI0/TI00.

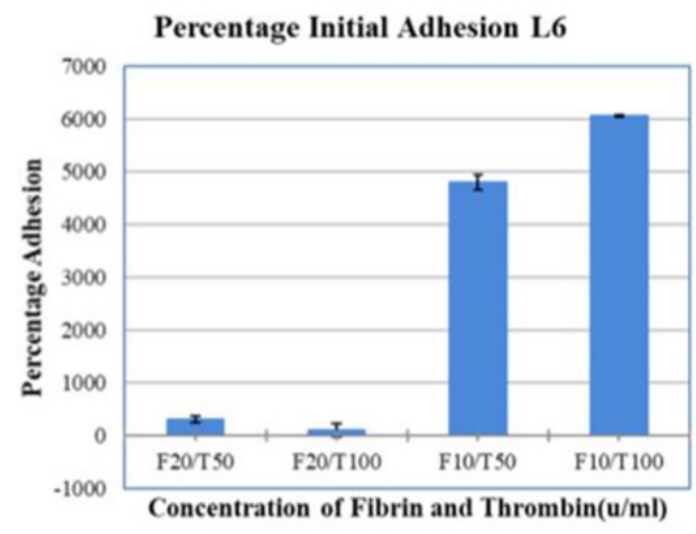

Figure 4 (b) L6 cell adhesion in several combinations of Fibrinogen and Thrombin: The best Adhesion was seen in FI0/TI00.

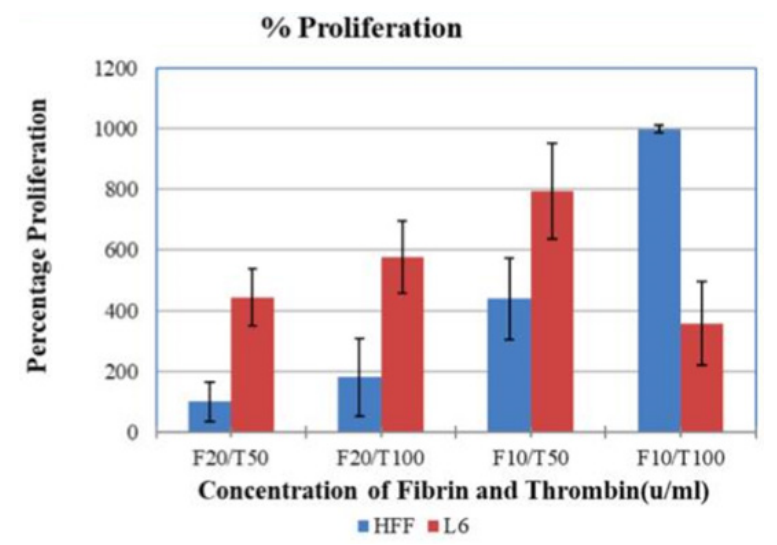

Figure 4 (c) HFF/L6 cells proliferation with different combinations of Fibrinogen and Thrombin:The best result for HFF was seen using FI0/TI00 \& the best result for $\mathrm{L} 6$ was seen using FI0/T50.

Higher concentrations of synthetic omega-3 decreases the initial adhesion and proliferation of HFF-I and L6 cells in a 3D construct

\section{HFF-I cells}

HFF-1 cells were treated in a 3D construct consisting of Fibrinogen and Thrombin in the presence of Synthetic Omega-3. The concentrations used as stated in the previous study were F10/ T100. This was to ensure a feasible environment for the HFF-1 cells. Synthetic Omega-3 concentrations were determined and placed in their respective wells. The concentrations of Synthetic Omega-3; 0, 0.1, 0.5 and $1 \mathrm{mg} / \mathrm{mL}$ respectively. The HFF-1 cells were plated on 2 different days and experimented on 3 different occasions for $n=6$ to analyze the initial adhesion and proliferation. After one hour of incubation higher concentrations of Synthetic Omega-3 decreased the adhesion of HFF1 cells. There was statistical significance between $0 \mathrm{mg} / \mathrm{mL}$ and $1 \mathrm{mg} /$ $\mathrm{mL}$ as seen in Figure 5A. Initial adhesion confirmed the presence of HFF-1 cells on Day 1. Cell proliferation is expressed as a percentage of the number of cells present on Day $1(100 \%)$. As seen in Figure 5B, HFF-1 cells proliferate more in the presence of $0.1 \mathrm{mg} / \mathrm{ml}$ of Synthetic Omega-3 on Day 7 in comparison to $1 \mathrm{mg} / \mathrm{mL}$ of Synthetic Omega-3. Overall the proliferation of HFF-1 cells also decreased in a 3D Fibrin construct with higher concentration of Synthetic Omega-3. The cell morphology was interesting, especially in a 3D Fibrin construct. Using a microscope capable of detecting fluorescence, HFF-1 cells were exposed to calcein and observed to achieve a visual reference of cell proliferation in the $3 \mathrm{D}$ fibrin construct. HFF-1 cell proliferation could be seen at lower concentrations of Synthetic Omega-3. HFF-1 cells begin to become elongated in the presence of $0.1 \mathrm{mg} / \mathrm{mL}$ of Synthetic Omega-3 which also had the highest proliferation in the study. The cell count decreases on Day 7 in the presence of $1 \mathrm{mg} / \mathrm{mL}$ of Synthetic Omega-3 as seen in Figure 5C. HFF-1 cells in the presence of higher concentrations of Synthetic Omega-3 are less confluent compared to lower concentrations of Synthetic Omega-3. Further comparisons will be made with L6 cells to determine if the various concentrations of Synthetic Omega-3 alter the cell proliferation and adhesion.

\section{L6 cells}

L6 cells were treated in a 3D construct consisting of Fibrinogen and Thrombin in the presence of Synthetic Omega-3. The concentrations used as stated in the previous study were F10/T100. This was to 
ensure a feasible environment for the HFF-1 cells. Synthetic Omega-3 concentrations were determined and placed in their respective wells. The concentrations of Synthetic Omega-3; 0, 0.1, 0.5 and $1 \mathrm{mg} / \mathrm{mL}$ respectively. The L 6 cells were plated on 2 different days of incubation and experimented on 3 different occasions for an $n=6$ to analyze the initial adhesion and proliferation.

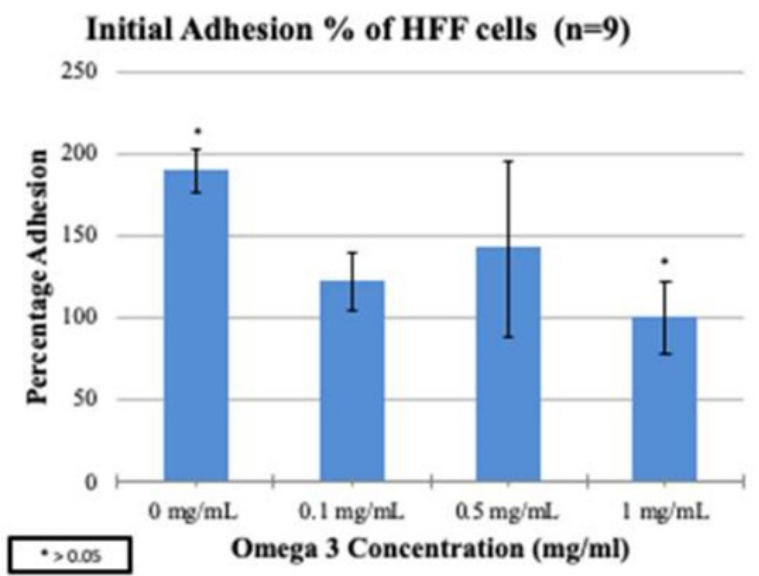

Figure 5 (a) HFF cell adhesion in the presence of Omega-3: Higher concentrations of Omega-3 decreased the adhesion of HFF cells.

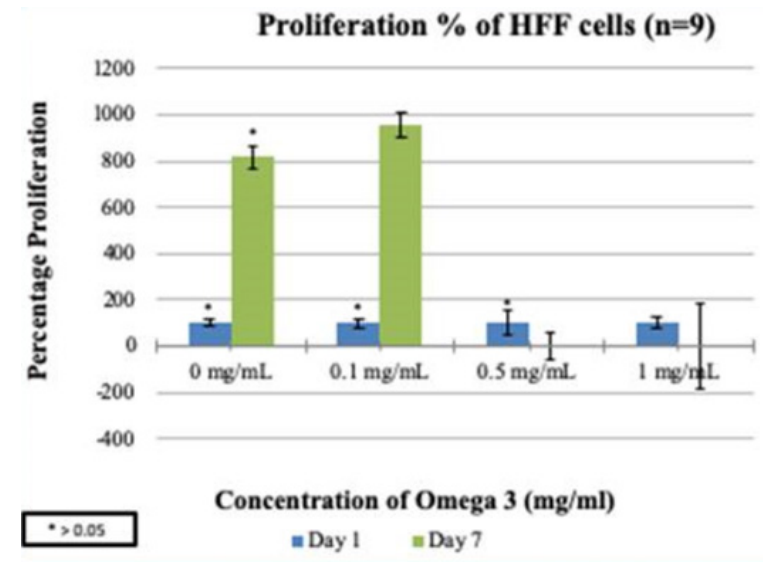

Figure 5 (b) HFF cell proliferation in the presence of Omega-3: Higher concentrations of Omega-3 decreased the proliferation of HFF cells.
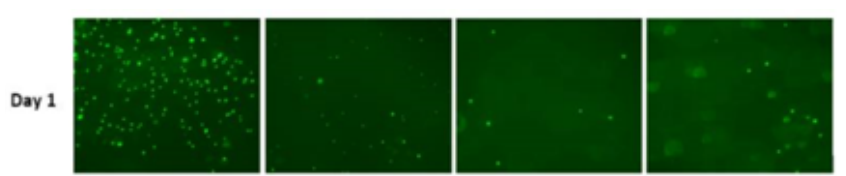

Day 7
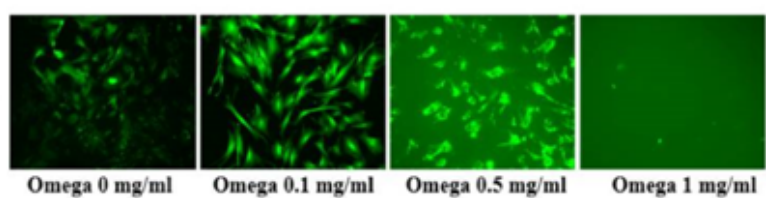

Figure 5 (c) HFF cells under exposure of calcein using a microscope capable of detecting fluorescence to have a visual reference of cell proliferation.

After one hour of incubation higher concentrations of Synthetic Omega-3 decreased the adhesion of L 6 cells. Initial adhesion confirmed the presence of L6 cells on Day 1. Cell proliferation is expressed as a percentage of the number of cells present on Day $1(100 \%)$. As seen in Figure 6A, L6 cells proliferate more in the presence of $0.1 \mathrm{mg} / \mathrm{ml}$ of Synthetic Omega-3 on Day 7 in comparison to $1 \mathrm{mg} / \mathrm{mL}$ of Synthetic
Omega-3. There was statistical significance between $0 \mathrm{mg} / \mathrm{mL}$ and $1 \mathrm{mg} / \mathrm{mL}$ as seen in Figure 6B. Overall the proliferation of L6 cells also decreased in a 3D Fibrin construct with higher concentrations of Synthetic Omega-3.

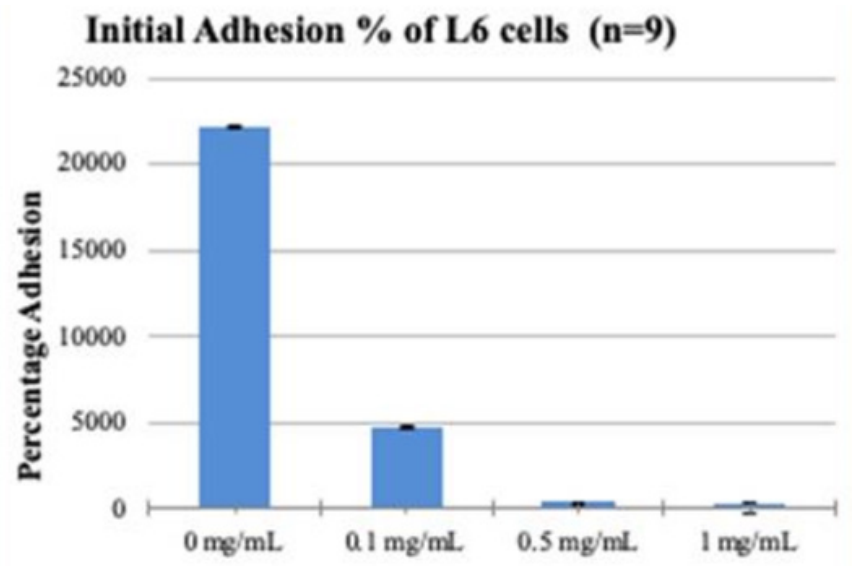

Omega 3 Concentration $(\mathrm{mg} / \mathrm{ml})$

Figure 6 (a) L6 cell adhesion in the presence of Omega-3: Higher concentrations of Omega- 3 decreased the adhesion of $L 6$ cells.

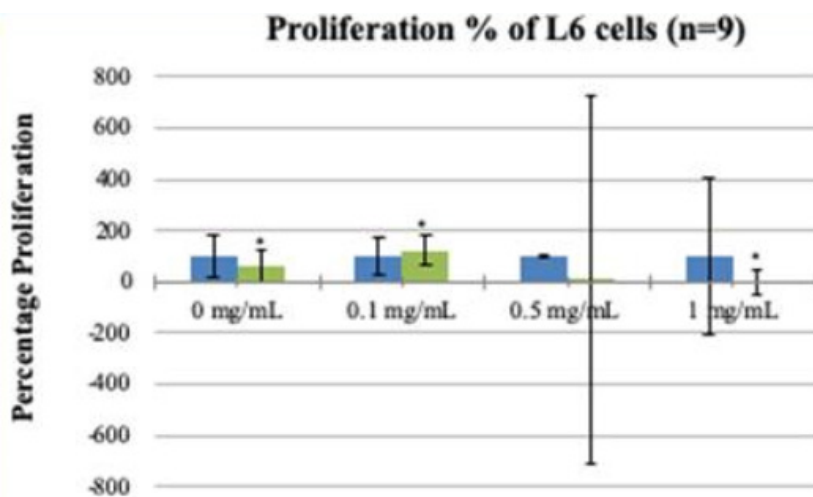

\section{Concentration of Omega $3(\mathrm{mg} / \mathrm{ml})$} =Day $1 \quad=$ Day 7

Figure 6 (b) L6 cell proliferation in the presence of Omega-3: Higher concentrations of Omega- 3 decreased the proliferation of HFF cells.

The cell morphology was evaluated in L6 cells in a 3D Fibrin construct. With the use of a microscope capable of detecting fluorescence, L6 cells were exposed to calcein and observed to achieve a visual reference of cell proliferation in the 3D fibrin construct. L6 cell proliferation could be seen at lower concentrations of Synthetic Omega-3. L6 cells remain rounded in lower concentrations of Synthetic Omega-3. They appear to be more confluent in the presence of $0.1 \mathrm{mg} /$ $\mathrm{mL}$ of Synthetic Omega-3 which also had the highest proliferation in the study. The cell count decreases on Day 7 in the presence of 1 $\mathrm{mg} / \mathrm{mL}$ of Synthetic Omega-3 as seen in Figure 6C. L6 cells in the presence of higher concentrations of Synthetic Omega-3 are less confluent compared to lower concentrations of Synthetic Omega-3. We evaluated this study in comparison with the Synthetic Omega-3 and HFF-1 cells. The results conclude that higher concentrations of Synthetic Omega-3 decrease the initial adhesion and proliferation of HFF-1 and L6 cells. 


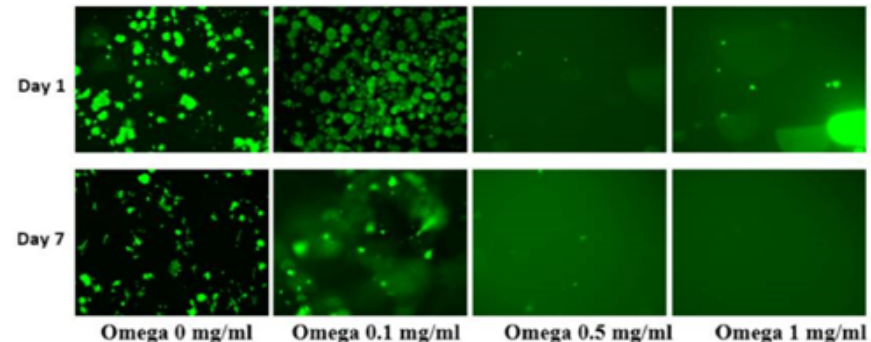

Figure 6 (c) HFF cells under exposure of calcein using a microscope capable of detecting fluorescence to have a visual reference of cell proliferation.

\section{Discussion}

In this study we examine the proliferation and adhesion of Human Foreskin Fibroblasts (HFF-1) and L6 muscle cells in the presence of Generic and Synthetic Omega-3. It has been stated that Omega-3 positively influence the cardiovascular health of an individual. Omega-3 does this so by lowering plasma triacylglycerols (TAGs) and increasing the high-density lipoproteins at the expense of low-density lipoproteins, as well as decreasing platelet aggregation..$^{20}$ This known fact shows that Omega-3s play an important role in cardiovascular metabolism and may not do so in muscular cell metabolism. Human Foreskin Fibroblasts (HFF-1) and L6 muscle cells were treated in different conditions to examine the proliferation and adhesion of cells. A 7-day experiment was conducted and ran three times to measure the interaction between the HFF-1 cells+ and L6 cells, and the proteins expressed. The experiment conducted showed the proliferation and adhesion of Human Foreskin Fibroblasts cells with Extracellular Matrix Proteins at different concentrations. Fibronectin is an ECM protein that is present in the tubulointerstitial of scarred kidneys. ${ }^{20}$ It seems the HFF-1 cells grew best in the condition dealing with Fibronectin with a concentration of $10 \mathrm{mg} / \mathrm{ml}$. The first experiment took a look at integrin-mediated cell adhesion to extracellular matrices and how this provides signals essential for cell cycle progression and differentiation. ${ }^{19}$ The experiment was conducted twice and analyzed how Human Foreskin Fibroblasts proliferate in different conditions over a 7-day period and results were recorded on Days 1,3 \& 7 $(\mathrm{n}=9)$. In both experiments $10 \mathrm{mg} / \mathrm{ml}$ of Fibronectin showed the best proliferation compared to the other conditions.

Furthermore, Human Foreskin Fibroblasts (HFF-1) and L6 cells were treated on a Fibronectin matrix in the presence of Generic Omega-3 to examine the proliferation and adhesion of cells. The data supports that Omega-3 slightly increases the adhesion of non-muscle cells. However, HFF-1 cells do not behave the same as L6 muscle cells in this study. A 7-day experiment was conducted and ran three times to measure the interaction between the HFF-1 and L6 cells and Generic Omega-3. Different concentrations of Generic Omega-3 were used and the experiment was conducted three times over a 7-day period and the results were recorded on Day1, Day $3 \& 7(n=9)$. The results show that the higher concentrations of Generic Omega-3 decreases the adhesion and proliferation of HFF-1 cells. Another alternative was measured to determine the proliferation and adhesion of HFF-1 and L6 cells. This was the introduction of Synthetic Omega-3 and how it impacts the behavior of HFF-1 and L6 cells.

HFF-1 and L6 muscle cells were also treated on a Fibronectin matrix in the presence of Synthetic Omega- 3 to examine the proliferation and adhesion of cells. A 7-day experiment was conducted and ran three times to measure the interaction between the HFF-1 and L6 cells and Synthetic Omega-3. Different concentrations of Synthetic
Omega-3 were used and the experiment was conducted three times over a 7-day period and the results were recorded on Day1, Day 3 \& $7(n=9)$. The results show that the higher concentrations of Synthetic Omega-3 decreases the adhesion and proliferation of HFF-1 and L6 cells. We could confirm on both, 2D \& 3D models this theory, with the exception of 2D HFF-1 where we believe it was human error. Omega 3 impacts cell adhesion and proliferation on muscle cells to the point it causes cell death. The addition of Omega- 3 fatty acids proved challenging as the solution was hard to initially work with and add homogeneously into the mixture of cells. Additionally, the PBS washes and the inversion method during calcein processing varied in the volumes added. Pictures seemed to have been taken at a different magnification. Trypsinization protocol had to be doubled, as the L6 cells did not completely detach in the first 7 minutes. However, depending on the person processing the plate, the interpretation of detachment was different. 4

While using this in a 3D construct, it was raised the possibility of use of Synthetic Omega-3 in 3D models in controlled concentrations to reduce proliferation due to its property of increasing the G1 phase in mitosis. Fibrin can also be used in many applications. Fibrin known as a homeostatic protein can be used to stop bleeding and as a delivery vehicle for cells in order to promote growth and heal wounds. ${ }^{14}$ Many applications also detail the impact of Fibrin and the stability of the construct that is being developed. This could be used specially in assays that would test mechanical properties in presence of cells. For example, tensile testing in gel. The data shows that the best proliferation is seen on the lower concentrations of Fibrinogen and higher concentrations of Thrombin. This is in accordance with what is seen in the literature, as when there are higher concentrations of Fibrinogen in the polymer, the porosity is lower, therefore promotes lower cell proliferation than the values seen with lower concentrations.

\section{Acknowledgments}

The authors would like to thank the Melissa McCoy for supporting the group through the experiments and encouraging the research.

\section{Conflicts of interest}

Authors declare that there is no conflict of interest.

\section{Funding}

California State University Channel Islands: Extended University. Department of Biotechnology, Biomedical Engineering Emphasis. One University Drive, Camarillo, California 93012.

\section{References}

1. Wei Z, Li D, Zhu L, et al. Omega 3 polyunsaturated fatty acids inhibit cell proliferation by regulating cell cycle in fad $3 \mathrm{~b}$ transgenic mouse embryonic stem cells. Lipids Health Dis. 2018;17(1):210.

2. E Bell, B Ivarsson, C Merrill. Production of a tissue-like structure by contraction of collagen lattices by human fibroblasts of different proliferative potential in vitro. Proceedings of the National Academy of Sciences. 1979;76(3):1274-1278.

3. https://commons.wikimedia.org/wiki/File:Chemist_pipetting.png

4. Bitterman PB, S I Rennard, S Adelberg, et al. Role of Fibronectin as a Growth Factor for Fibroblasts. J Cell Biol. 1983;97(6):1925-1932.

5. GY Liu, Agarwal R. Templated Assembly of Collagen, Fibers Directs Cell Growth in 2D and 3DK. 
6. Boyden Chamber Technique.

7. Duong H, Wu B, Tawil B. Modulation of 3D fibrin matrix stiffness by intrinsic fibrinogen-thrombin compositions and by extrinsic cellular activity. Tissue engineering. Part A. 2009;15(7):1865-1876.

8. Pankov R, Yamada KM. Fibronectin at a glance. Journal of cell science. 2002;115(20):3861-3863.

9. Valentine RC, Valentine DL. Omega-3 fatty acids in cellular membranes: a unified concept. Progress in lipid research. 2004;43(5):383-402.

10. HFF-1 (ATCC) SCRC-1041.

11. Calder PC. $\mathrm{n}^{-} 3$ polyunsaturated fatty acids, inflammation, and inflammatory diseases. The American journal of clinical nutrition. 2006;83(6):1505S-1519S.

12. Calder PC. Marine omega-3 fatty acids and inflammatory processes: effects, mechanisms and clinical relevance. Biochimica et Biophysica Acta (BBA)-Molecular and Cell Biology of Lipids. 2015;1851(4):469-484.

13. De Caterina R, Cybulsky MI, Clinton SK, et al. The omega-3 fatty acid docosahexaenoate reduces cytokine-induced expression of proatherogenic and proinflammatory proteins in human endothelial cells. Arteriosclerosis and thrombosis: a journal of vascular biology. 1994;14(11):1829-1836.

14. Cox S, Cole M, Tawil B. et al. Behavior of human dermal fibroblasts in three-dimensional fibrin clots: dependence on fibrinogen and thrombin concentration. Tissue engineering. 2004;10(5-6):942-954.

15. Reinertsen E, Skinner M, Wu B, et al. Concentration of fibrin and presence of plasminogen affect proliferation, fibrinolytic activity, and morphology of human fibroblasts and keratinocytes in 3D fibrin constructs. Tissue Engineering Part A. 2014;20(21-22):2860-2869.

16. Brown AC, Barker TH. Fibrin-based biomaterials: modulation of macroscopic properties through rational design at the molecular level. Acta biomaterialia. 2014;10(4):1502-1514.

17. Miron-Mendoza M, Graham E, Manohar S, et al. Fibroblast-fibronectin patterning and network formation in 3D fibrin matrices. Matrix Biology. 2017;64:69-80.
18. Illingworth DR, Harris WS, Connor WE. Inhibition of low density lipoprotein synthesis by dietary omega-3 fatty acids in humans. Arteriosclerosis: An Official Journal of the American Heart Association, Inc., 1984;4(3):270-275.

19. Garcia AJ, Vega MD, Boettiger D. Modulation of cell proliferation and differentiation through substrate-dependent changes in fibronectin conformation. Molecular biology of the cell. 1999;10(3):785-798.

20. Jeromson S, Gallagher IJ, Galloway SD, et al. Omega-3 Fatty Acids and Skeletal Muscle Health. Marine drugs. 2015;13(11):6977-7004.

21. Schwalfenberg GK. The alkaline diet: is there evidence that an alkaline $\mathrm{pH}$ diet benefits health? Journal of environmental and public health. 2011;2012:727630.

22. Dawson-Hughes B, Harris SS, Ceglia L. Alkaline diets favor lean tissue mass in older adults. The American journal of clinical nutrition. 2008;87(3):662-655.

23. McDowall, Jennifer. Fibrinogen, Wound Healing. Eu-ropean Bioinformatics Institute GB. 2006.

24. Calcein AM. R\&D Systems Inc., 2018.

25. Nicoletti Giovanni. Effects of a spring water on human skin fibroblast in vitro cultures: preliminary results. Acta Vulnological. 2016;14(4):196201.

26. Grazi E. Water and muscle contraction. International journal of molecular sciences. 2008;9(8):1435-1452.

27. McNamara CA. Thrombin stimulates proliferation of cultured rat aortic smooth muscle cells by a proteolytically activated receptor. Journal of clinical investigation. 1993;91(1):94-98.

28. Chiu CL, Hecht V, Duong H, et al. Permeability of three-dimensional fibrin constructs corre-sponds to fibrinogen and thrombin concentrations. BioRe-search open access. 2012;1(1):34-40.

29. Vavken P, Joshi SM, Murray MM. Fibrin concentration affects ACL fibroblast proliferation and collagen synthesis. The Knee. 2010;18(1):4246. 